\title{
Paradoxical Reaction to Golimumab: Tumor Necrosis Factor $\alpha$ Inhibitor Inducing Psoriasis Pustulosa
}

\author{
Marien Siqueira Soto Lopes ${ }^{a} \quad$ Beatriz Moritz Trope ${ }^{a}$ \\ Maria Paula Rua Rochedo Rodriguez ${ }^{\mathrm{a}}$ Rachel Lima Grynszpan ${ }^{\mathrm{a}}$ \\ Tullia Cuzzi ${ }^{b} \quad$ Marcia Ramos-e-Silva ${ }^{a}$ \\ ${ }^{a}$ Sector of Dermatology and Post-Graduation Course - HUCFF-UFRJ and School of \\ Medicine, and ${ }^{b}$ Sector of Pathology, University Hospital and School of Medicine, \\ Federal University of Rio de Janeiro, Rio de Janeiro, Brazil
}

\section{Key Words}

Golimumab · Psoriasis pustulosa - Tumor necrosis factor $\alpha$ inhibitor $\cdot$ Paradoxical reaction

\begin{abstract}
Importance: Golimumab is a human monoclonal antibody, used for rheumatoid arthritis, psoriatic arthritis and ankylosing spondylitis. Adverse reactions are increasing with this class of medication (tumor necrosis factor $\alpha$ inhibitors). Observations: The authors present a case of a female patient who presented with psoriasis pustulosa after the use of golimumab for rheumatoid arthritis. Conclusions and Relevance: Paradoxically, in this case, golimumab, which is used for psoriasis, induced the pustular form of this disease. We are observing an increasing number of patients who develop collateral effects with tumor necrosis factor $\alpha$ inhibitors, and the understanding of the mechanism of action and how these adverse reactions occur may contribute to avoid these sometimes severe situations.
\end{abstract}

(C) 2013 S. Karger AG, Basel

\section{Introduction}

Psoriasis, which affects $0.1-3 \%$ of the population, is a chronic inflammatory disease characterized by the production of cytokines mediated by T-lymphocytes that boost hyperproliferation and abnormal differentiation of keratinocytes [1]. Factors known to interfere in the occurrence and worsening of psoriasis are trauma, physical and emotional stress, cold and dry climate, excessive alcohol and drug consumption. It is also known that 
some medications, such as antimalarials, nonsteroidal anti-inflammatories and beta blockers, are involved in the triggering of the disease in patients without a previous or familial history [2].

Curiously, inhibitors of the tumor necrosis factor alpha (TNF- $\alpha$ ), used in treatment of rheumatoid and psoriatic arthritis, ankylosing spondylitis and severe psoriasis, can lead to development of psoriasis and psoriasiform eruptions [3]. The paradoxical reaction of a disease induced by the medication indicated for its treatment encouraged us to report the case of a patient using golimumab, a TNF- $\alpha$ inhibitor, who developed psoriasis.

\section{Case Report}

A female, 50-year-old, black patient with rheumatoid arthritis, followed-up by the Rheumatology Sector, was forwarded to the Dermatology Ambulatory as an emergency case due to complaints of sudden onset of pustular lesions in the palms and soles (fig. 1, fig. 2), and erythematous-desquamating plaques with pustules in the limbs, chest and dorsum (fig. 3). During anamnesis, we found that the patient had recently begun the use of golimumab, a TNF- $\alpha$ inhibitor, and that she was on her fourth monthly dose of the medication. The clinical picture began soon after administration of this last dose and she was also using methotrexate concurrently. The patient had no previous personal or familial history of psoriasis. A skin biopsy was carried out with clinical suspicion of pustular psoriasis by paradoxical effect, since there are literature reports of similar adverse events with other TNF- $\alpha$ inhibitors. We decided to suspend the medication, given the extension of the cutaneous picture. Histopathology showed abundant neutrophilic infiltrate (Munro's abscess), acanthosis, presence of Kogoj's spongiform pustule, and dilation of papillary dermal capillaries (fig. 4, fig. 5). The clinical-histopathologic correlation confirmed the diagnosis of pustular psoriasis. We continued treatment with methotrexate $15 \mathrm{mg}$ for a week, in an attempt to treat the cutaneous-articular manifestations. The patient is undergoing ambulatory follow-up, but, after over 12 months of suspension of the drug, she still has skin lesions, with periods of exacerbation and appearance of new lesions, providing evidence of triggering a new disease caused by the use of the medication.

\section{Discussion}

The drug used by the patient was golimumab, a TNF- $\alpha$ inhibitor. This substance is a human monoclonal antibody produced by a line of murine hybridoma cells using a recombining DNA technology. It forms, with high affinity, stable complexes with the bioreactive form, whether soluble or transmembrane TNF- $\alpha$, that prevent connection of TNF- $\alpha$ to its receptors. It is indicated for treatment of rheumatoid arthritis, psoriatic arthritis and ankylosing spondylitis. Administration is a monthly subcutaneous injection.

The full mechanism of the action of TNF- $\alpha$ inhibitors remains unknown, but their multiple effects on the immune system are well known [4].

The most common already reported secondary effects of TNF- $\alpha$ inhibitors are pain, edema and eczema at the injection sites, as well as herpes simplex, bacterial infection, lichenoid eruption, multiform erythema, lupus erythematosus, acute generalized exanthematic pustulosis and lymphoma [5]. Paradoxically, those same TNF- $\alpha$ inhibitors can induce or aggravate psoriasis $[1,3,6]$. The incidence of induced psoriasis by TNF- $\alpha$ inhibitors was estimated at $2.3-5 \%$ [1]. More than half of these patients presented palmoplantar pustules 
[1]. The underlying mechanisms of the paradoxical event still remain unknown, but plasmacytoid dendritic cells (PDCs) and interferon- $\alpha$ (IFN- $\alpha$ ) seem to be key factors.

TNF- $\alpha$ plays an important role in the regulation of IFN- $\alpha$ production and also in the inhibition of the hematopoietic PDC progenitor maturation. The inhibition of TNF- $\alpha$ may favor an abnormal production of IFN- $\alpha$ by PDCs [1]. There is clinical evidence that the unbalance of IFN- $\alpha$ worsens psoriasis [6] and there are reports in the literature where a worsening of psoriasis occurred after injection of recombining IFN-TNF and application of imiquimod cream, with PDCs infiltrating the skin with psoriasis [7]. This way, by suppressing TNF- $\alpha$, an increased intensity of PDC maturation would occur, increasing the production of IFN- $\alpha$ and leading to the paradoxical reaction.

\section{Conclusion}

The case presented here adds to the increasing number of patients that developed collateral effects during treatment with TNF- $\alpha$ inhibitors. However, more studies are necessary to determine the true incidence and the nature of these adverse reactions. The understanding of the action mechanism should contribute to improving the treatment of the cases and in an ideal situation identify risk patients precociously.

\section{Disclosure Statement}

The authors have no conflict of interest for this publication.

\section{References}

1 de Gannes GC, Ghoreishi M, Pope J, Russell A, Bell D, Adams S, et al: Psoriasis and pustular dermatitis triggered by TNF-alpha in patients with rheumatologic conditions. Arch Dermatol 2007;143:223-231.

$\$ 2$ Dika E, Varotti C, Bardazzi F, Maibach HI: Drug-induced psoriasis: an evidence-based overview and the introduction of psoriatic drug eruption probability score. Cutan Ocul Toxicol 2006;25:1-11.

3 Choi YJ, Kim DS, Park JM, Oh SH, Park YK, Lee JH: A case of psoriasiform eruption triggered by tumor necrosis factor alpha antagonist therapy. Korean J Dermatol 2008;46:721-723.

4 Tracey D, Klareskog L, Sasso EH, Salfeld JG, Tak PP: Tumor necrosis factor antagonist mechanisms of action: a comprehensive review. Pharmacol Ther 2008;117:244-279.

5 Romero-Mate A, Garcia-Donoso C, Cordoba-Guijarro S: Efficacy and safety of etanercept in psoriasis/psoriatic arthritis: an updated review. Am J Clin Dermatol 2007;8:143-155.

-6 Collamer AN, Guerrero KT, Henning JS, Battafarano DF: Psoriatic skin lesions induced by tumor necrosis factor antagonist therapy: a literature review and potential mechanisms of action. Arthritis Rheum 2008;59:996-1001.

7 Nestle FO, Conrad C, Tun-Kyi A, Homey B, Gombert M, Boyman O, et al: Plasmacytoid predendritic cells initiate psoriasis through interferon-alpha production. J Exp Med 2005;202:135-143. 
Lopes et al.: Paradoxical Reaction to Golimumab: Tumor Necrosis Factor $\alpha$ Inhibitor Inducing Psoriasis Pustulosa

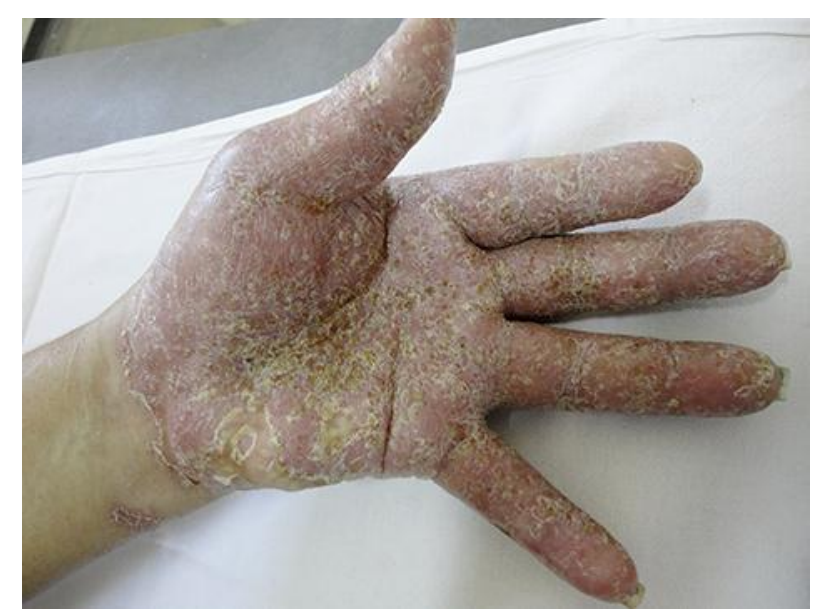

Fig. 1. Pustular palmar lesions, associated with erythema and desquamation.

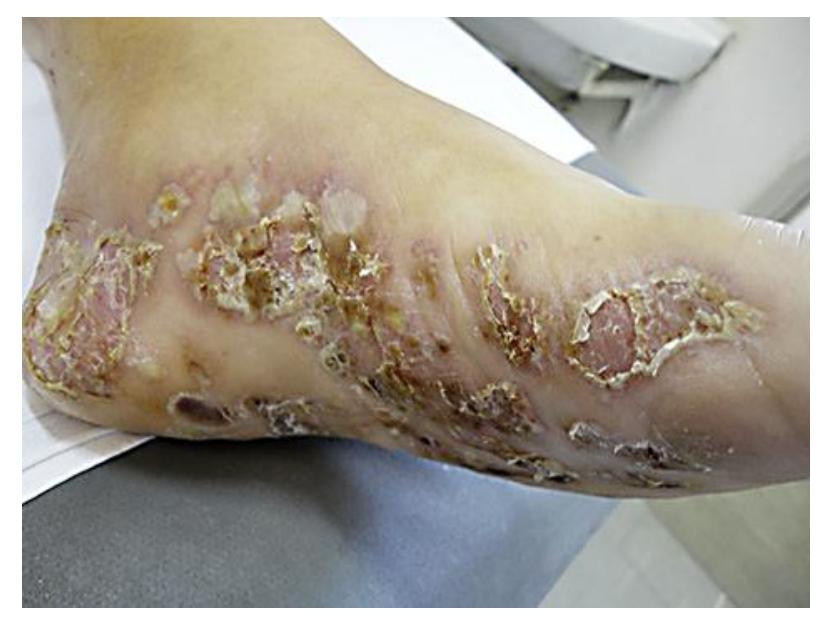

Fig. 2. Pustular lesions on the soles. 


\section{Case Reports in Dermatology}

\begin{tabular}{l|l}
\hline Case Rep Dermatol 2013;5:326-331 \\
\hline DOI: $10.1159 / 000350930$ & $\begin{array}{l}\text { C 2013 S. Karger AG, Basel } \\
\text { www.karger.com/cde }\end{array}$ \\
\hline
\end{tabular}

Lopes et al.: Paradoxical Reaction to Golimumab: Tumor Necrosis Factor $\alpha$ Inhibitor Inducing Psoriasis Pustulosa

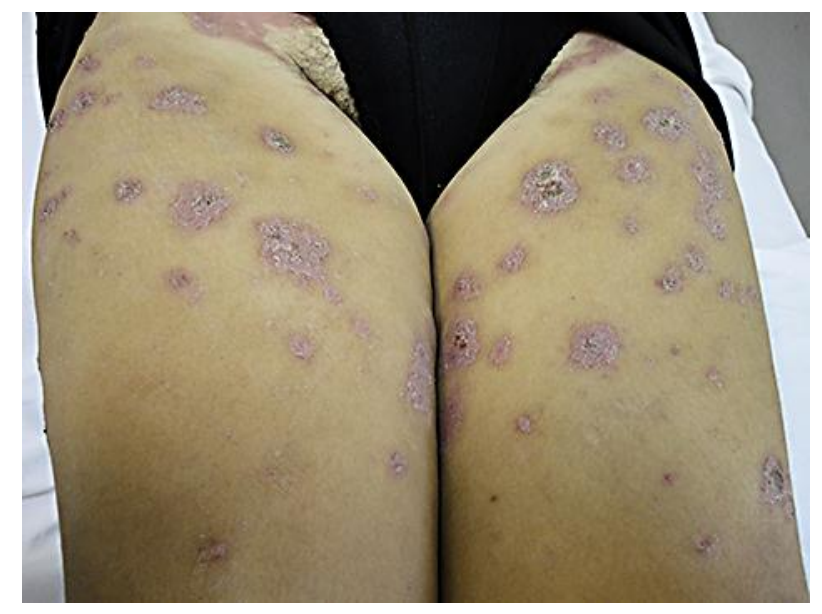

Fig. 3. Pustules in the center of erythematous-desquamative lesions of the lower limbs.

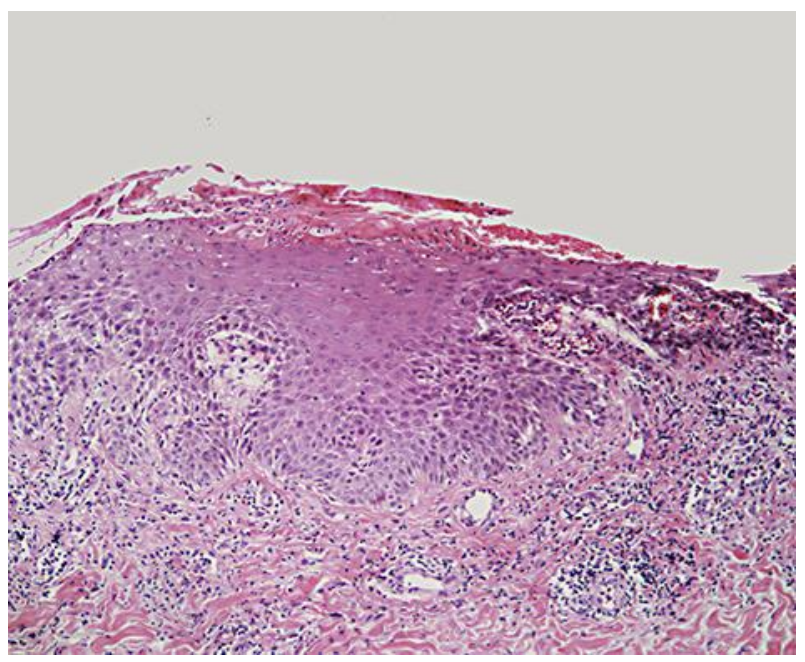

Fig. 4. Epidermis with acanthosis and exuberant exocytosis of neutrophils, which in segment configure Kogoj's spongiform pustule; note also dilation of the capillaries of the papillary dermis. HE. $\times 10$. 
Lopes et al.: Paradoxical Reaction to Golimumab: Tumor Necrosis Factor $\alpha$ Inhibitor

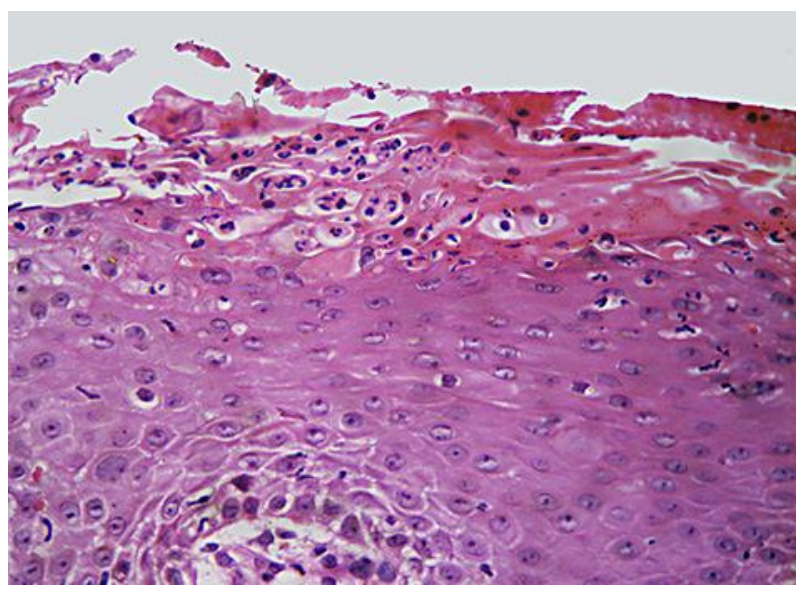

Fig. 5. Detail of Kogoj's spongiform pustule: accumulation of neutrophils in the upper portions of the Malpighi layer. HE. $\times 40$. 